\title{
LANDSCAPE ANALYSIS TECHNIQUES APPLIED TO A BUDDHIST CARVED ROCK SCULPTURE
}

\author{
Giuseppe Salemi ${ }^{1}$, Emanuela Faresin ${ }^{1}$, Luca Maria Olivieri ${ }^{2}$ \\ ${ }^{1}$ Dept. of Cultural Heritage: Archaeology and History of Art, Cinema and Music, University of Padua, Piazza Capitaniato 7, 35139, \\ Padua, Italy - (giuseppe.salemi, emanuela.faresin@unipd.it) \\ ${ }^{2}$ Dept. of Asian and North African Studies, Cà Foscari University of Venice, Cà Cappello, San Polo, 2035, Calle del Magazen, \\ 30125, Venezia, Italy - lucamaria.olivieri@unive.it
}

KEY WORDS: landscape analysis, DEM, 3D model, structured light scanner, geomorphons, Buddhist sculptures.

\begin{abstract}
:
The Swat valley (Pakistan) has always been considered an important center of Gandhara art. Due to the unfavourable conditions, this artistic phenomenon has long been almost ignored or underestimated, but its documentation is essential for study the symbolism of the figures, their spatial organization, their stylistic variation and their conservative state. The methodology proposed in this project starts form the 3D acquisition with a structured light system in order to obtain a 3D high resolution model of Buddhist carved rock sculpture. From the 3D geometry, The Digital Elevation Model is produced. This DEM is the starting points for the surface analysis using Remote Sensing approaches for classify landforms using pattern recognition. The surface is considered as a landscape, where carved are valleys bordered by slopes and crests. Hillshading, slope analysis and geomorphons are used in order to highlight the surface feature, to "read" all the details not visible due to the bad condition and to map surface state of conservation.
\end{abstract}

\section{INTRODUCTION}

Buddhist rock sculptures flourished in Swat valley (Pakistan) from seventh to eight century and they are located along the left tributaries of the Swat river where the natural condition has favored the urban settlement (Filigenzi, 1999).

The general appearance of rock sculpture is characterized by a rich but somehow limited iconographic repertoire (an all-male pantheon) displayed in its specific attributes (Filigenzi, 2003).

The classification of the rock sculptures, in terms of stylistic and iconographic criteria, is difficult because of the poor conservation and the objective bad conditions of the surface.

The damage caused by the atmospheric agents, has been further getting worse by iconoclastic acts. For these reasons, systematic archaeological investigations and studies have been carried out since 1956 by the Archaeological Mission in Pakistan (MAI) of the IsMEO/IsIAO (now ISMEO and Ca' Foscari University of Venice) with the Department of Archaeology \& Museums, Govt. of Pakistan (DOAM) (Filigenzi, 1999).

Moreover, from September 2007, in collaboration with the Department of Cultural Heritage (University of Padua), a complete 3D survey of the stele was carried out and a group of 17 stelae, preserved at the Swat Archaeological Museum of Saidu Sharif (Ashraf Khan, 1993) was acquired with a structured light system. In a previous work (Faresin and Salemi, 2019) these stelae were studied with algorithms used in remote sensing: Slope and Curvature, Local Relief Model and Sky View Factor, Positive and Negative Openness.

The aim was to evaluate the ability of these algorithms to highlight iconographic details in order to increase the artistic information.

In this paper we want to go forward the previous work (Faresin and Salemi, 2019) and applied landscape analysis techniques (hillshading, slope analysis and geomorphons) to maps the "landform" elements on the basis of "geomorphometric variables" (Evans, 1972; Pike, 1988; Mac Millan et al., 2004; Olaya, 2013). These attributes and landform types were extracted from a DEM that was obtained from a 3D high resolution model. The carved rock was analyzed as a landscape in which its features such as valley, ridges, peak, pits or anomalies related to the surface are identified. The goal is to use these types of landscape analysis to highlight the surface and the iconographic feature and details, to "read" all the elements not visible due to the bad condition and to map the state of conservation and the deteriorated area.

\section{MATERIAL AND METHODS}

\subsection{Buddhist carved rock sculpture}

In order to test and to evaluate the capability of these landscape analysis to reach our goal and to answer to our questions, a very complex stele (in terms of dimension, iconographic details and state of conservation) was chosen (Filigenzi, 2015; Sardar, 2003).

Stele 16.

Inv. Rep. S39 Triad (Buddha and bodhisattvas); Stele, roundish shape (Figure 1).

"Cons.: badly abraded, especially the upper part of the figure; corrosion; lime incrustations.

Mat.: [white marble]

Meas. $(\mathrm{cm})$ : from the right: $76(68-63)$ x 22 × $5 ; 107(84-75) \times$ 59 x 11; 73 (67-63) x 20 x 5" (Filigenzi 2015: 195).

Buddha in padmāsana with uncovered feet, and dhyānamudrā, with plain nimbus with plain border and flaming edge; throne with turned legs and backrest, with bordered drape which falls over the centre. The throne is supported by two standing lions

* Corresponding author 
viewed frontally, which raise and turn their heads looking symmetrically at the Buddha. At the sides, two bodhisattvas, with plain nimbus, standing frontally on a raised full-blown lotus, with paridhāna and uttarīya, short flat decorated necklace, pendant earrings. The bodhisattva (Vajrapāni??) to the viewer's right shows the right hand at the shoulder possibly holding a vajra (?), and the left hand on the hip. The second bodhisattva (Padmapāni) with knotted belt visible, shows the right hand in varadamudrā, and the left hand at the shoulder holding a lotus flower by its long stem.

"Simplified volumes, geometric pattern of figures, visible above all in the triangular profile of the Buddha's legs; the bodhisattva figures display a pronounced bending; they have narrow waist, round flanks, massive rigid lower limbs; sketchy drapery consisting of closely-spaced parallel lines" (Filigenzi 2015: 195).

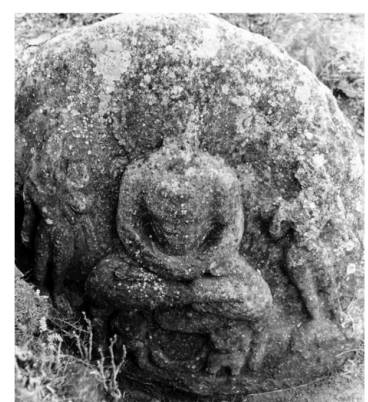

Figure 1. Stele 16; triad (Buddha and bodhisattvas) Photo Luca M. Olivieri IsMEO, 1989.

\subsection{D high resolution model}

The methodology proposed in this project starts form the 3D acquisition with a structured light system to obtain a $3 \mathrm{D}$ model with micrometer resolution of the Buddhist carved rock sculpture (Figure 2).

The 3D model is a measurable representation of an object through the representation of its morphological and morphometric characteristics (Soler et al., 2017). The structured light technique belongs to the active methods and uses a projection device to project structured patterns.

The scene is then captured by a digital image detector and processed in order to reconstruct the geometry from the deformation of the pattern in the digital image. The method is accompanied by texture acquisition (Zhang, 2018).

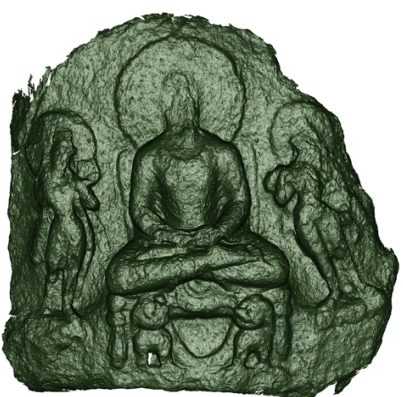

Figure 2. 3D high resolution model obtained by the processing of 113 scans and composed by 5054199 vertices.

The instrument used for the acquisition is Cronos Dual (www.faro.com). Data were computed with Optical RevEng 2.4 SR 8 Pro following the standard steps of the 3D scanning pipeline (point cloud acquisition, point cloud alignment, meshing, mesh editing) (Soler et al., 2017; Faresin and Salemi, 2019; Zhiliang and Shilong, 2018).
The $3 \mathrm{~d}$ model dataset descriptive parameters and the hardware and software characteristics are summarized in Table 1.

\begin{tabular}{|c|c|}
\hline Hardware & Software \\
\hline $\begin{array}{c}\text { Cronos Dual } \\
\text { (Open Technologies } \\
\text { rebranded Faro }\end{array}$ & $\begin{array}{c}\text { Optical RevEng } 2.4 \\
\text { SR } 8 \text { Pro }\end{array}$ \\
\hline \multicolumn{2}{|c|}{ Descriptive global dataset parameters } \\
\hline $\begin{array}{c}\text { \# scans } \\
\text { Standard deviation } \\
\text { \#points } \\
\text { \#triangles } \\
\end{array}$ & $\begin{array}{c}113 \\
0,0276 \mathrm{~mm} \\
142910180 \\
5054199 \\
\end{array}$ \\
\hline \multicolumn{2}{|c|}{ Meshing phase parameters } \\
\hline Tool & Values \\
\hline $\begin{array}{c}\text { Smoothing } \\
\text { Smoothing type } \\
\text { Sharpening Strenght } \\
\text { Tolerance }(\mathrm{mm})\end{array}$ & $\begin{array}{c}2.0 / 10.00 \\
\text { projective } \\
5.0 / 5.0 \\
0.0250 \mathrm{~mm}\end{array}$ \\
\hline
\end{tabular}

Table 1. 3D model global dataset descriptive parameters and the setting parameters for "sculptures" meshing tool.

\subsection{Surface analysis: hillshading, slope analysis, geomorphons}

From the 3D high resolution model, the Digital Elevation Model was computed. This DEM is the starting point for the surface analysis developed with Remote Sensing algorithms. All data were processed with QGIS 3.14.16 with GRASS 7.8.3. The Digital Elevation Model in grey scale (Figure 3a). of colour gives the possibility to do a first evaluation of the surface elevation and understand which parts of the iconographic subject are more protruding. With the Digital Elevation Model in false colour map (Figure $3 b$ ), where blue represents the minumun elevation and red the maximum one, even the micro differences in eight are visible (for example the legs or the lions on the bottom).
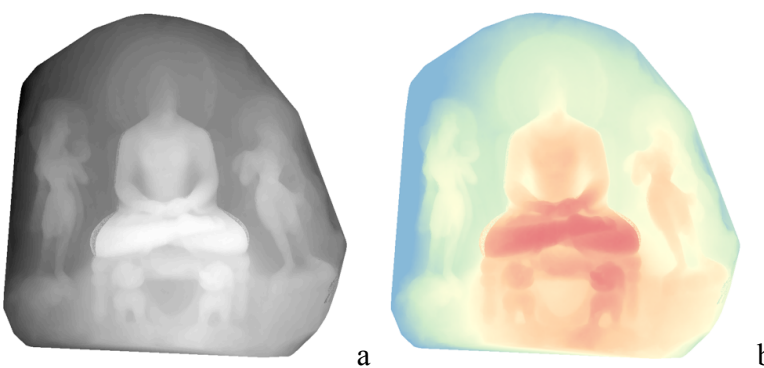

Figure 3. The DEM in grey colour scale (a) and the DEM with a colour scale (b).

On this DEM, three different landscape analysis techniques were applied: hillshading, slope analysis and geomorphons.

The relief shading method, often refereed as hillshading, has a long tradition in cartographic representation of terrain.

Hillshading algorithms are based on the cosine law and adapted to shaded relief. The parameters extracted are: $\mathrm{Z}$ factor: 1 , Azimuth: $300,000^{\circ}$, Vertical angle: $40,000^{\circ}$. The aim is to generate shaded relief maps which emphasise structures that are obliquely illuminated, but hide those that are illuminated along the perpendicular axis (Veronesi and Lorenz, 2015).

Calculation of slope maps from altitude matrices is directly analogous to the use of gradient operators in image processing. Slope analysis is defined as the maximum rate of change in elevation between each cell and its neighbours (Warren et al. 
2004). It was obtained from the first derivate of the DEM with $z$ factor 1 .

The method of geomorphons has been developed for classifying landforms using pattern recognition, rather than differential geometry (Jasiewicz and Stepinski, 2013). In its simplest expression, the $3 \times 3$ local neighbourhood around a central cell is examined. The eight neighbours are marked ad (-) if they are lower, $(+)$ if they are higher, and (0) for equal elevation. Each cell is therefore defined by a string of eight labels, an 8-tuple pattern, representing a geomorphon. The relationship between the central cell and its neighbours is based on visibility.

A ternary pattern characterizing terrain type in the neighbourhood of the central cell is determined not from simple differences in elevations, but rather from a quantity $\Delta$ which is derived through characterization of the local surface using the line-of-sight principle. This principle, originally proposed in connection with the notion of terrain openness (Yokoyama et al., 2002), relates surface relief and horizontal distance by means of so-called zenith and nadir angles along the eight principal compass directions.

To calculate zenith and nadir angles at a central cell, eight elevation profiles starting at the central cell and extending along the principal directions up to the "lookup distance" $L$ are extracted from the DEM. An elevation angle is the angle between the orizontal plane and a line connecting the central cell with a point located on the profile. An elevation angle is negative if the point on the profile has an elevation lower than the central cell.

For each profile a set of elevation angles ${ }_{D} S_{L}$ is calculated; the symbol denoting this set indicates a dependence on direction (D) and lookup distance or scale $(L)$. The zenith angle of a profile is defined as $\mathrm{D} \phi \mathrm{L}=90^{\circ}-\mathrm{D} \beta \mathrm{L}$, where $\mathrm{D} \beta \mathrm{L}$ is the maximum elevation angle in $\mathrm{DS}_{\mathrm{L}}$. Similarly, the nadir angle of a profile is defined as $\mathrm{D} \psi \mathrm{L}=90^{\circ}-\mathrm{D} \delta \mathrm{L}$, where $\mathrm{D}^{\delta} \mathrm{L}$ is the minimum elevation angle in $\mathrm{DS}_{\mathrm{L}}$. Thus, the zenith angle is an angle between the zenith and the line- of-sight, and the nadir angle is an angle between the nadir and a hypothetical line-ofsight resulting from reflecting an elevation profile with respect to the horizontal plane. Both zenith and nadir angles are positively defined and have a range from $0^{\circ}$ to $180^{\circ}$.

The value of a slot in a ternary pattern corresponding to direction $\mathrm{D}$ and lookup distance $L$ is denoted by a symbol $\mathrm{D} \Delta \mathrm{L}$ and given by the formula:

$D \Delta L=\left\{\begin{array}{ccc}1 & \text { if } & D \psi L-D \phi L>t \\ 0 & \text { if } & |D \psi L-D \phi L|<t \\ -1 & \text { if } & D \psi L-D \phi L b-t\end{array}\right.$

There are two free parameters in the above formula, one is the lookup distance $L$ and the other is the flatness threshold $t$.

The advantage of using a line-of-sight based neighbourhood instead of a grid-based neighbourhood in calculating ternary patterns becomes clear by observing that, in principle, choosing an infinitely large value of $L$ should result in identification of landform element regardless of its scale. In practice, by using larger values of $L$, we can simultaneously identify landform elements on a wider range of scales than it would be possible with the grid-based neighbourhood (Jasiewicz and Stepinski, 2013).

There are theoretically $3^{8}=6561$ different (ternary) patterns. This numbers can be reduced to 498 because of the presence of many duplicates after rotation and/or reflection. As this number is still too high for mapping, geomorphons are grouped in classes corresponding to the ten most common landforms: flat, summit, ridge, shoulder, spur, slope, hollow, footslope, valley and depression (Monna et al., 2018)

The values were extracted with an inner search radius of $1 \mathrm{~cm}$.

\section{RESULTS}

The methodology proposed produces $2.5 \mathrm{D}$ raster maps, which can be studied individually, but also they can be integrated to produce a descriptive and interactive map where the single layer could be turn off or on.

The hillshading image (Figure 4a) allows to detect the third dimension and it is possible to appreciate the volume of the figure that seems to be extruded. Moreover, thanks to the binomial light and shadows, the morphological iconographic details are highlight and the type of manufacturing become visible deeply much better than the original (see Figure 1). It is important to underline that these observations are made with a static source of the light, but it is possible to moving the point of illumination in a new "game" of light and shadows that emphasize other, and maybe new, details.
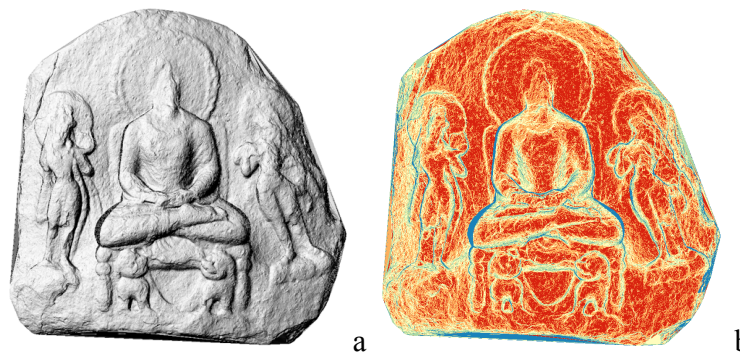

Figure 4. The hillshade map which revels the protruding parts and gives the perception of the volumes (a). The slope analysis

map highlights the border of the iconographic subjects.

The slope map (Figure 4b), which represents the local magnitude of the maximum gradient in degrees, represents the area with a significant depth change respect to the point of view of the observer. This map offers a clear distinction between the iconographic features and the surrounding surface. It is an image with an objective and mathematical interpretation of the surface without "game" of light that could distort the perception.

The geomorphons approach provides a discretized classification where hollows, footslopes, valley and depression are more particularly sought because they may correspond to the carved and deteriorated area.

The pattern based approach and the analysis of the single 10 layer corresponding to the 10 most common geomorphons, shows the total absence of the summit and ridge types and the presence of shoulder (Figure 5a) pattern. This proves that the surface is mostly smooth without the presence of peaks.

On the basis of this identification the following step consists in isolating valley (Figure $5 \mathrm{~b}$ ) and depression because the resulting map, highlights the area of interest in a more accurate way. This strategy keeps out the rest of landforms, here considered useless for this precise goal.

It is immediately clear as where the relief is more exposed (chest, hands, legs, the area surrounding the face along the circular hen) the surface is compromised. 


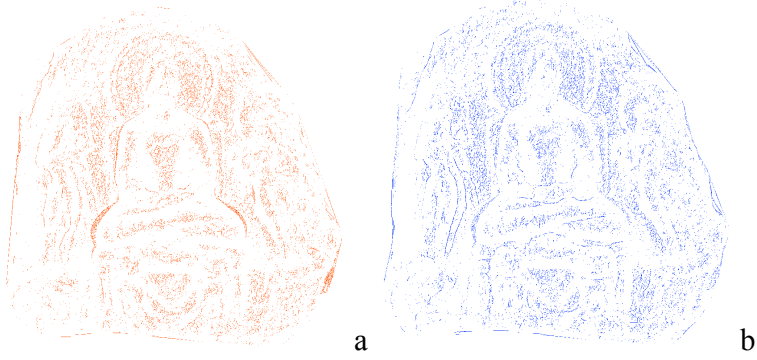

Figure 5. Pattern based approach with shoulder (a) and valley (b) geomorphons which map the more exposed and compromised areas.

\section{DISCUSSION}

Stele S39 was initially photographed in situ near the locality of Shanglo in the Jambil Valley. In the spring of 2018, the stele which was thought to be lost, was found by the assistants of the Italian Archaeological Mission and transported first to the Mission House. Once cleaned and re-photographed the stele was inventoried and then transported to the Swat Museum, where it is now displayed in the front garden. Both operations were carried out under the supervision of the Museum Director, Mr Faizurahman. Once the documentation that is the subject of this article was completed, all the details that had already been assumed in the autopsy analysis in situ (Filigenzi 2015: 195) were confirmed.

To summarize all the computing steps of the project a "mental map" was realized to focus the flowchart of the work starting from the 3D model to the surface analysis (Figure 6).

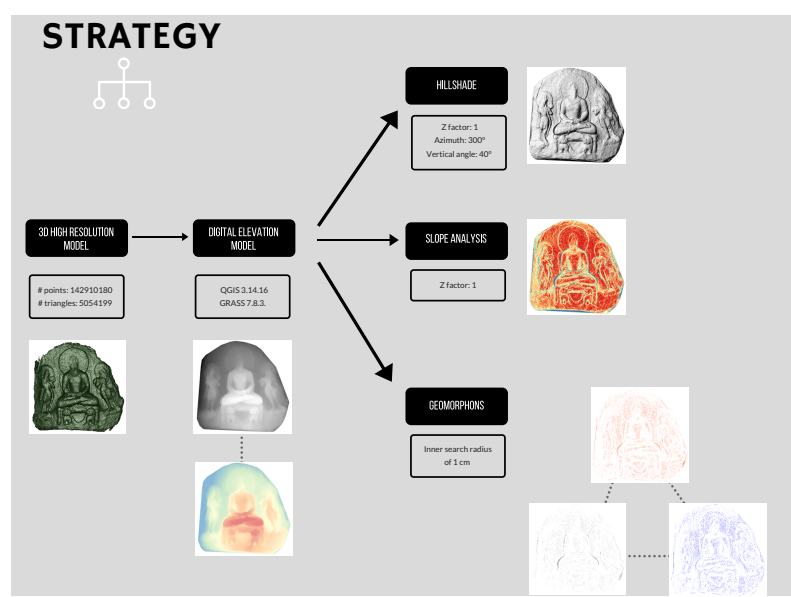

Figure 6. The "mental map". The arrows shaped objects show the consequentiality of the single processing step; instead, the dotted lines represent the correlation between the results.

The upper part of the stele can be read more clearly: the nimbus is certainly decorated with an external flaming edge. Important details of the throne, including the function of the two lions (clearly supporting the throne, as well as the position of the muzzles facing upwards, i.e. towards the Buddha, in an attitude of veneration), are clearer now. Details of the figure of Padmapāni can also be read more clearly, for example its knotted belt, while the figure to the left of the Buddha can be now clearly recognised as a Vajrapāni. The new documentation has also made it possible to potentially associate this stele with the one preserved at the Metropolitan Museum of Art, New York (no. 1995.570.2). The two stelae show similarities in the type of stone, part of the details, treatment of volumes and composition, to the extent that one would be led to believe that they were made in the same area and at the same time. Certainly, therefore the MMA stele comes from Swat, possibly from the Jambil valley, and should be associated, like our S39 stele, with one of the large surviving eight century stupas of Arabut, Jurjurai or Loebanr.

Considering the heterogeneity of the material, it can be reasonably stated that each analysis have contributed to defining the rock sculpture.

The combination of the results and the overlapping of the single layers (Figure 7), give a map that describes in a punctually way the surface features, the iconographic details, all the elements not visible due to the bad condition and the state of conservation with its relative deteriorated area.

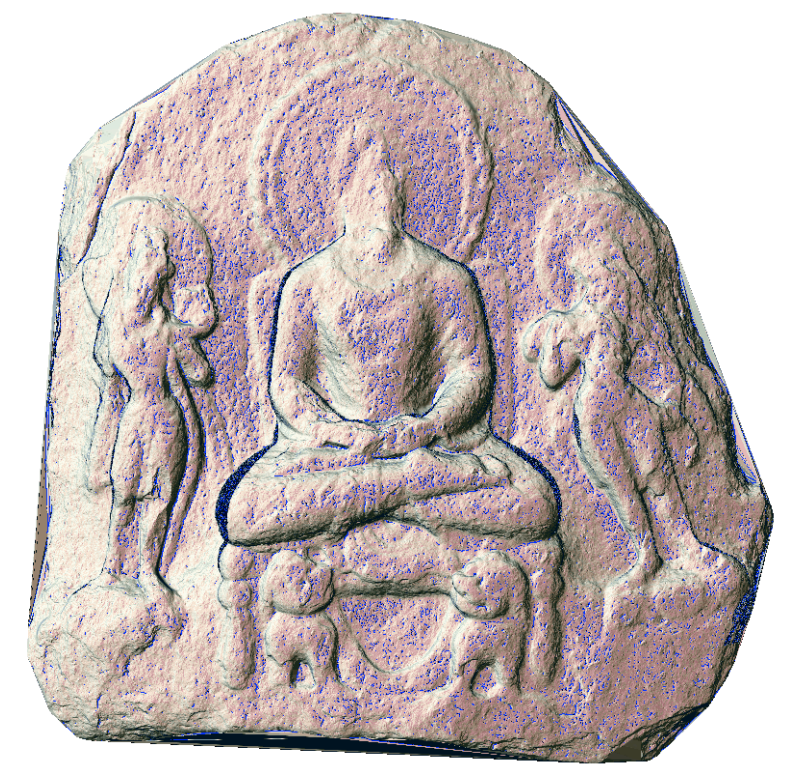

Figure 7. Descriptive map coming from the combination of the single results overlapping hillshading, slope analysis, valley and depression (geomorphons) layers.

\section{CONCLUSIONS}

The key in this project is the interdisciplinary: the synergy between archaeology, new technologies and remote sensing. The results of this synergy can be surprising.

In a previous works, recently published (Faresin and Salemi, 2019; Srinivasan et al., 2019), we tried to propose a reading of a stele with a complex iconography that is difficult to read through the enhancing of the volumetric features using the geomorphons.

In this case, we chose a stele in which the number of unclear details was, on the whole, limited, in order to test and improve the process with landscape analysis (DEM, hillshading and slope). The results in both cases were particularly important, and we hope to apply the landscape analysis method soon to a larger number of stelae from the same context.

A pipeline is provided for the acquisition of $3 \mathrm{D}$ high resolution models of the carved rock. It consists in acquiring the object by a structured light system, producing DEM, calculating slope, the hillshade and the geomorphons. The methodology proposed is not invasive and it is easy to implement in this field of research. It produces $2.5 \mathrm{D}$ raster maps which can be studied individually but also they can be integrated in order to produce a descriptive and interactive map where the single layer could be turn off or on based on the single questions.

Starting from the Digital Elevation Model it is possible study which parts of the iconographic subject are more protruding 
even for the micro differences in eight. With the 3D model the third dimension is registered and with the hillshading image it is possible to appreciate the volume of the figure that seems to be extruded. Moreover, thanks to the binomial light and shadows, the morphological iconographic details are highlight and the type of manufacturing become visible.

Slope analysis computs a mathematical interpretation of the surface and gives a clear distinction between the iconographic borders and the surrounding surface.

Geomorphons, allows to classify where hollows, footslopes, valley and depression are more particularly sought because they may correspond to the carved and deteriorated area.

\section{REFERENCES}

Ashraf Khan, M., 1993: Gandhara Sculptures in the Swat Museum. Archaeological Museum.

Evans, I., 1972: General geomorphometry, derivatives of altitude and descriptive statistics. In Chorley, R.J. (eds.) Spatial analysis in geomorphology. Harper \& Row, 17-90.

Faresin, E., Salemi, G., 2019: Buddhist Stele of Swat Valley: point cloud analysis and interpretation. ISPRS Archives, XLII2/W18, 31-37. doi.org/10.5194/isprs-archives-xlii-2-w18-312019.

Filigenzi, A., 1999: Il Bodhisattva Maitreya nell'arte rupestre dello Swat. Appunti sull'iconografia e sul culto del Buddha venturo. 1st ed. Istituto Italiano per l'Africa e l'Oriente, Roma.

Filigenzi, A., 2015: Art and landscape: Buddhist rock sculptures of late antique Swat/Uddiyana. Verlag der Osterreichischen Akademie der Wissenshaften, Wien.

Filigenzi, A., 2003: A Vajrayanic Theme in the Rock Sculpture of Swat. In Verardi, G., Vita, S., (eds.), Conference of Buddhist Studies, 37-55.

Jasiewicz, J., Stepinski, T.F., 2013: Geomorphon - a pattern approach to classification and mapping of landform. Geomorphology, 182, 147-156. doi.org/ 10.1016/j.geomorph.2012.11.005.

Mac Millan, R., Jones, R., Mc Nabb, D., 2004: Define a hierarchy of spatial entities for environmental analysis and modeling using digital elevation models (DEMs). Computers, Environment and Urban System, 28(3), 175-200. doi.org/10.1016/S0198-9715(03)00019-X.

Monna, F., Esin, Y., Magail, J., Granjon, L., Navarro, N., Wilczek, J., Saligny, L., Couette, S., Dumontet, A., Chateau, C., 2018: Documenting carved stones by 3D modeling - example of Mongolian deer stones. Journal of Cultural Heritage, 34, 116-128. doi.org/10.1016/j.culher.2018.04.021.

Olaya, V., 2013: Basic land-surface parameters. In Hengl, T., Reuter, H. (eds.) Geomorphometry, Concepts, Software, Application. Elsevier, 147-156.

Pike, R., 1988: The geometric signature: quantifying landslideterrain types from digital elevation models. Mathematical Geology, 20(5), 491-511. doi.org/10.1515/geo-2020-0187.
Sardar, B., 2003: The catalogue of stelae explored by various archaeological mission in Swat Valley. Journal of Civilisation, 26(1), 1-54

Soler, F., Melero, F.J., Luzòn, M.V., 2017: A complete 3D information system for cultural heritage documentation. Journal of Cultural Heritage, 23, 49-57. doi.org/10.1016/j.culher.2016.09.008.

Srinivasan Meth, D., Olivieri, L.M., Salemi, G., 2019: The Eight-Armed Devi from Guligram, Swat (c. $8^{\text {th }}$ century CE). A study in three parts dedicated to the memory of herald Hauptmann, Gandhāran Studies, 12, 105-128.

Veronesi, F., Lorenz, H., 2015: A GIS tool to increase the visual quality of relief shading by automatically changing the light direction. Computers \& Geosciences, 74, 121-127. doi.org/10.1016/j.cageo.2014.10.015.

Warren, S.D., Hohmann, M.G., Anerswald, K., Mitasova, H., 2004: An evaluation of methods to determinate slope using digital elevation data. Catena, 58(3), 215-233. doi.org/10.1016/j.catena.2004.05.001.

Yokoyama, R., Shirasawa, M., Pike, R.J., 2002: Visualizing topography by openness: a new application of image processing to digital elevation model. Photogrammetry engineering and remote sensing, 68(3), 257-266.

Zhang, S., 2018: High-speed 3D shape measurements with structured light method: a review. Optics and Lasers in Engineering, 106,

119-131. doi.org/10.1016/j.optlaseng.2018.02.017.

Zhiliang, M., Shilong, L., 2018: A review of 3D reconstruction techniques in civil engineering and their applications. Advanced $\begin{array}{llll}\text { Engineering Informatics, } & 37, & 163-174\end{array}$ doi.org/10.1016/j.aei.2018.05.005. 